\title{
Influência da poluição aérea gerada pelo tráfego veicular na produção do óleo essencial e das atividades antifúngica e citotóxica in vitro de Cyrtocymura scorpioides (Lam.) H.Rob. (Asteraceae)
}

\begin{abstract}
LEITE, P.O.'; SOARES, C.P.2; MORAIS, F.V.2; MENEGON, R.F.3; JOAQUIM, W.M. ${ }^{2}$
1 Universidade do Vale do Paraíba -UNIVAP - Programa de Pós-Graduação em Ciências Biológicas, Av. Shishima Hifumi, 2911, Urbanova, CEP 12244-00, São José dos Campos - São Paulo, Brasil; ‘Universidade do Vale do Paraíba - UNIVAP, Instituto de Pesquisa e Desenvolvimento - IP\&D/UNIVAP, Av. Shishima Hifumi,

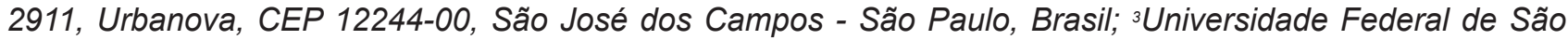
Paulo - UNIFESP, Rua São Nicolau, 210, Centro, CEP 09913-030, Diadema, São Paulo, Brasil *Autor para correspondência: oliveira-patricia@hotmail.com
\end{abstract}

RESUMO: Cyrtocymura scorpioides (sin. Vernonia scorpioides (Lam.) Pers.), Piracá é utilizada popularmente para tratamento de úlceras, traumatismos, candidíase, processos inflamatórios e dores musculares. Objetivou-se verificar nas plantas cultivadas na Vila Nair, Jardim São Dimas e Urbanova em São José dos Campos - SP, a influência da poluição veicular nos rendimentos da matéria seca (folhas), no óleo essencial, e no extrato bruto, bem como a ação citotóxica em células HEP-2 e L929, e identificar os componentes do óleo essencial e ação fungicida em Candida albicans. As estacas (54) foram cultivadas durante 6 meses em solo + adubo (2:1) na Universidade do Vale do Paraíba - UNIVAP, e distribuídas nas estações Dutra (E1 - tráfego intenso), Teotônio (E2 - tráfego médio) e Urbanova (E3 - tráfego baixo), onde 18 mudas foram cultivadas durante 6 meses, sendo 3 repetições de 6 plantas. O óleo essencial foi extraído por hidrodestilação e seus componentes identificados por cromatografia gasosa acoplado a espectrômetro de massas (CG-MS), através de indice de similaridade com a base de espectros Wiley L. O extrato bruto foi concentrado por rotavapor. A ação fúngica foi avaliada pelo teste de difusão em disco e a citotoxicidade pelo teste MTT. Em Urbanova (E3) verificouse maior rendimento da matéria seca, do extrato bruto e do óleo essencial. Identificou-se no óleo essencial: ß-cariofileno, a-cariofileno, germacreno $D$, delta-cadineno e cariofileno. O Óleo Essencial possui possui baixa ação fungicida em C. albicans, enquanto o extrato hidroalcóolico se mostrou citotóxico para L929 e HEp-2.

Palavras-chave: Cyrtocymura scorpioides, Óleo essencial, Citotoxicidade, Ação fungicida.

\begin{abstract}
Air pollution influence generated by vehicular traffic in essential oil production and antifungal and cytotoxic activities in vitro Cyrtocymura scorpioides (Lam.) H.Rob. (Asteraceae). Cyrtocymura scorpioides (syn. Vernonia scorpioides (Lam.) Pers.), known as Piracá, is popularly used for the treatment of ulcers, trauma, candidiasis, inflammatory disorders, and muscle pain. This study aimed to assess the influence of vehicular pollution on the yield of dry matter (leaves), essential oil, and crude extract, and the cytotoxic action in HEP-2 and L929 cells. This study also aimed to identify the components of the essential oil, and verify its fungicidal action against Candida albicans in plants grown in Vila Nair, Jardim São Dimas, and Urbanova, São José dos Campos - SP, Brazil. The seedlings (54) were grown in soil + fertilizer (2:1) at the Universidade do Vale do Paraiba - UNIVAP, and distributed to different stations, Dutra (E1 - heavy traffic), Teotônio (E2 - medium traffic), and Urbanova (E3 - low traffic), where 18 seedlings were cultivated for 6 months, with 3 replicates of 6 plants. The essential oil was extracted by hydrodistillation and its components were identified by by Gas chromatography mass spectrometry (GC-MS), with a similarity index computed using the Wiley L spectra. The crude extract was concentrated in a Buchi Rotary Evaporator R-114, the fungicidal action and cytoptoxicity were evaluated using the disk diffusion method and the MTT test, respectively. In
\end{abstract}

Recebido para publicação em 02/02/2015

Aceito para publicação em 04/07/2015

10.1590/1983-084X/15_016

Rev. Bras. PI. Med., Campinas, v.18, n.1, p.27-37, 2016. 
Urbanova (E3), high yields of dry matter, crude extract, and essential oil were obtained. The following components were identified in the oil: $\beta$-caryophyllene, $\alpha$-caryophyllene, germacrene $D$, delta-cardinene, and caryophyllene oxide. The oil was found to have low fungicidal action against C. albicans, while the hydroalcoholic extract was cytotoxic to L929 and HEP-2.

Keywords: Cyrtocymura scorpioides, Essential Oil, Cytotoxicity, Fungicidal Action.

\section{INTRODUÇÃO}

Cyrtocymura scorpioides (Lam) H. Rob. (Asteraceae), (sin Vernonia scorpioides) (Lam) Pers. que apresenta atividade cicatrizante, antiinflamatória (Carrenho, 2009), vem sendo cultivada em quintais e utilizada popularmente na região sul de Minas Gerais e na região do Vale do Paraíba em São Paulo para dores musculares, candidíase e úlceras.

Dreux, (2005) verificou no extrato hidroalcoólico da planta, a presença de ativos antiedematogênicos frente ao veneno de Bothrops fonsecai, tais como: alcalóides, flavonóides, taninos e saponinas. Buskuhl, (2007) obteve rendimento de $0,16 \%$ do óleo essencial das folhas de $C$. scorpioides de espécies cultivadas no Brasil, sendo encontrados os compostos $\alpha$-cariofileno, germacreno-D e biciclogermacreno.

A cidade de São José dos Campos - SP, considerada com potencial de poluição atmosférica, é cruzada no sentido transversal pela Rodovia Presidente Dutra BR-116, onde circulam 80 mil veículos/dia, abrigando grandes indústrias, em uma região topográfica de vale que favorece a baixa dispersão atmosférica (São Paulo, 2012).

As alterações no metabolismo secundário de plantas são decorrentes de níveis elevados de ozônio $\left(\mathrm{O}_{3}\right)$, Nitratos $\left(\mathrm{NO}_{x}\right)$ e monóxido de carbono (CO) na atmosfera, além de reduzir taxas fotossintéticas, provocar necroses, cloroses entre outros efeitos fisiológicos nas plantas (Moraes, 2012).

Objetivou-se estudar Cyrtocymura scorpioides cultivada em três bairros na cidade de São José dos Campos-SP, em função de constatar na literatura a inexistência de pesquisas em outras localidades referentes à influência da poluição gerada pelo tráfego veicular no rendimento do óleo essencial, do extrato bruto, ação citotóxica do extrato hidroalcóolico em células HEp-2 e L929, e identificar no óleo essencial, por CG-MS, os componentes presentes verificando a ação fungicida do óleo essencial em Candida albicans.

\section{MATERIAL E MÉTODO}

O trabalho foi conduzido na cidade de São José dos Campos nos bairros, Vila Nair, com intenso tráfego de veículos, às margens da Rodovia Presidente Dutra, nas coordenadas $23^{\circ} 12^{\prime} 22.91^{\prime \prime} S$ $45^{\circ} 53^{\prime} 02.17$ ", Dutra (E1), na Avenida Teotônio Vilela no Jardim São Dimas, médio tráfego de veículos nas coordenadas: $23^{\circ} 11^{\prime} 45.27^{\prime \prime} S 45^{\circ} 53^{\prime} 05.93^{\prime \prime}$, Teotônio (E2), no Centro de Estudos da Natureza - CEN da Universidade do Vale Paraíba - UNIVAP, no Urbanova, com baixo tráfego de veículos, nas coordenadas $23^{\circ} 12^{\prime} 53.20^{\prime \prime S} 45^{\circ} 57^{\prime} 30.20^{\prime \prime}$, Urbanova (E3).

A planta, identificada, realizada pela Profa. Dra. Rosangela Simão Bianchini, está depositada no Herbário do Jardim Botânico/ Instituto de Botânica (IBOT-SP) com o Voucher Number: SP 452867.

\section{Cultivo da planta}

As mudas de Cyrtocymura scorpioides, foram acondicionadas em sacos de polipropileno de 5L, contendo como substrato: solo + adubo (Pó de serragem: 50 I, Calcário: 0,5\%, NPK 4148: 0,25 $\%$, Pó de osso: 0,5\%, Superfosfato simples: 0,5\%) na proporção 2:1 o qual foi analisado no Laboratório de Análise de Solos da Universidade de Taubaté UNITAU. As mudas aclimatadas por 20 dias, foram obtidas a partir de estacas apicais $(15 \mathrm{~cm})$ oriundas de planta matriz cultivada no viveiro de plantas medicinais no Centro de Estudos da Natureza - CEN, na Universidade do Vale do Paraíba - UNIVAP.

Utilizou-se 54 mudas, das quais foram distribuídas 18 mudas, com repetições de 3 mudas, em cada estação, Dutra (E1), Teotônio (E2) e Urbanova (E3), onde foram cultivadas entre (01 de maio a 01 de novembro de 2013), irrigadas três vezes por semana. Após esse período coletaram-se as folhas no dia 02 de novembro de 2013.

\section{Extração do óleo essencial}

A obtenção do óleo essencial foi realizada por hidrodestilação (Alvarez et al., 2013), à partir de $100 \mathrm{~g}$ de folhas frescas em clevenger com balão de $1 \mathrm{~L}$., contendo 0,6 L de água destilada. Em seguida o óleo essencial foi pesado e quantificado em termos de porcentagem a partir da massa inicial (Simões \& Spitzer 2004), no Laboratório de Ciências Farmacêuticas da Faculdade de Ciências da Saúde FCS, da Universidade do Vale do Paraíba - UNIVAP.

\section{Preparação do extrato}

O extrato foi preparado em Soxhlet (Cintra \& Damasceno, 2010). $10 \mathrm{~g}$ de folhas de cada local foram secas em estufa FANEM modelo $502 \mathrm{~A}$, a $60^{\circ} \mathrm{C}$ por 48 horas e pulverizadas com $200 \mathrm{~mL}$ de 
etanol $70 \%$; em seguida, o extrato foi concentrado em rotavapor BUCHI R-114, no Laboratório de Biologia Celular Tecidual da Universidade do Vale do Paraíba - UNIVAP.

\section{Identificação dos compostos presentes no óleo essencial}

Os compostos presentes no óleo essencial das amostras cultivadas nos 3 locais, foram identificados e quantificados por cromatografia gasosa acoplado com espectrômetro de massas (CG-MS) Shimadzu modelo GC 17AAF, coluna Rtx-5MS: $30 \mathrm{~m} \times 0,25 \mathrm{~mm} \times 0,25 \mu \mathrm{m}-5 \%$ difenil $95 \%$ polisiloxano, velocidade de fluxo $0,8 \mathrm{~mL} / \mathrm{min}$ e carreado por gás hélio, na Central Analítica da Universidade Federal de São Paulo (UNIFESP), Campus Diadema. A identificação dos compostos foi realizada por análise de índice de similaridade utilizando a base de espectros Wiley L. Os espectros de massas foram gravados a partir de $30-450 \mathrm{~m} / \mathrm{z}$ (Vasincu et al., 2014).

\section{Atividade fungicida do óleo essencial}

A atividade fungicida do óleo essencial foi realizada no Laboratório de Biologia Molecular e Celular da Universidade do Vale do Paraíba UNIVAP. A Candida albicans TCC 1023, foi obtida do Núcleo de Estudos em Farmácia e Biomedicina - NUFABI, da Universidade do Vale do Paraíba UNIVAP. Utilizou-se o teste de difusão em disco, sendo a cultura de $C$. albicans inoculada por espalhamento na superfície em placa de petri (90x15) contendo: meio Sabouraud, $5 \times 10^{4}$ células (500 $\mu \mathrm{L}$ do preparado celular), discos de papel de filtro estéreis ( $5 \mathrm{~mm}$ de diâmetro) dispostos sobre o meio de cultura na placa de petri, em triplicata, distantes entre si $1,5 \mathrm{~cm}$. Pipetou-se aos discos 10 $\mu \mathrm{L}$ da solução contendo o óleo, $14 \mathrm{mg} / \mathrm{ml}$ (menor concentração obtida através do rendimento do óleo essencial) extraído de cada estação (E1, E2, E3), diluídos em DMSO (Maia, 2010). Como controle negativo utilizou-se $10 \mu \mathrm{L}$ de DMSO, e como controle positivo $10 \mu \mathrm{L}$ de anfotericina $B 100 \mathrm{mg} / \mathrm{mL}$, droga utilizada para o tratamento de infecções fúngicas inclusive por Candida albicans (Burgess et al. 2000). As placas foram incubadas por 48 horas a $37^{\circ} \mathrm{C} \mathrm{e}$ em seguida fotografadas para a verificação do halo formado (Vasconcelos et al. 2012).

\section{Citotoxicidade do extrato}

O teste de MTT (3-(4,5-dimetiltiazol-2yl) 2,5-difenil brometo de tetrazolina) - (Sigma-Aldrich), foi utilizado para verificar a viabilidade celular. As células foram incubadas por 24 horas com os extratos de $C$. scorpioides e cultivadas nas 3 estações: Dutra (E1), Teotônio (E2), Urbanova (E3), nas concentrações de $1 \mathrm{mg}, 0,5 \mathrm{mg}$ e $0,25 \mathrm{mg}$ e solubilizados em etanol $70 \%$. O teste teve inicio com a dose máxima de $1 \mathrm{mg}$, usualmente utilizada, para se verificar o início da taxa de morte celular, até chegar à dose que não cause a total destruição da células e, como teste controle, utilizou-se o etanol $70 \%$. No teste MTT, as células HEp-2 e L929 plaqueadas separadamente a uma densidade de $1 \times 10^{5}$ por poço em placas de 24 poços, cada um contendo $200 \mu \mathrm{L}$ de meio MEM (com $10 \%$ de SFB e de $1 \%$ antibiótico e antimicótico) - (GIBCO, Life Technology), foram incubadas por 24 horas, a $37^{\circ} \mathrm{C}$. Adicionou-se sobre as culturas de células, cultivadas em triplicata, as concentrações dos extratos ( $1 \mathrm{mg} / \mathrm{mL}, 0,5 \mathrm{mg} / \mathrm{mL}$ e $0,25 \mathrm{mg} / \mathrm{mL})$ nos demais poços adicionou-se pedaços de látex, papel de filtro e um somente com células, constituindo os grupos controle, negativo e positivo. As culturas foram incubadas por períodos de 24 e 48 horas. Os poços foram lavados com PBS, onde se adicionou

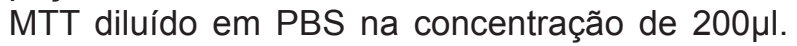
As células foram incubadas por 60 minutos a $37^{\circ}$ $\mathrm{C}$ em estufa. Posteriormente, foi adicionado às placas $200 \mu \mathrm{l}$ de DMSO por poço, e em seguida as placas foram agitadas por 60 minutos para diluição dos cristais. A leitura da absorbância $(570 \mathrm{~nm})$ das placas, foi realizada em espectrofotômetro (Elisa Spectracount Packard, EUA). A citotoxicidade foi avaliada estatisticamente por análise de variância (ANOVA), com nível de significância de 5\%. A comparação das médias, foi realizada pelo teste de Tukey (Silva, 2012).

\section{RESULTADO E DISCUSSÃO}

Constatou-se a diferença estatística na massa da matéria seca(g) de C. scorpioides cultivada nas estações Urbanova (E3) (316g), em relação às demais estações Dutra (E1) e Teotônio (E2), que não diferiram entre si, (Tabela 1), portanto, a estação que apresentou maior rendimento da matéria seca foi (E3), $316 \mathrm{~g}$, com o menor tráfego veicular, seguida de (E2) com $164 \mathrm{~g}$, com tráfego veicular médio, e (E1) com 79g, com tráfego veicular intenso.

Olivares, (2003) realizou estudos com Tithonia diversifolia, (Asteraceae), cultivada próxima a rodovias com intenso tráfego e com baixo tráfego veicular, verificando que as plantas submetidas ao intenso tráfego apresentaram menor massa foliar e aumento na concentração de fenóis. Verificou-se que $C$. scorpioides apresentou menores valores de massa seca nas estações Dutra (E1) com $79 \mathrm{~g}$ e Teotônio (E2) com $164 \mathrm{~g}$, quando comparado à estação Urbanova (E3) com $316 \mathrm{~g}$, entretanto, no que se refere aos metabólitos secundários, o tráfego intenso promoveu também os menores rendimentos do óleo essencial (Tabela 2), sugerindo que embora

Rev. Bras. PI. Med., Campinas, v.18, n.1, p.27-37, 2016. 
TABELA 1. Massa de matéria seca das folhas de Cyrtocymura scorpioides cultivada nas diferentes estações Dutra (E1), Teotônio (E2) e Urbanova (E3).

\begin{tabular}{lll}
\hline Dutra (E1) & Teotônio (E2) & Urbanova (E3) \\
R1: $90 \mathrm{~g}$ & R1: $157 \mathrm{~g}$ & R1: $323 \mathrm{~g}$ \\
R2: $57 \mathrm{~g}$ & R2: $188 \mathrm{~g}$ & R2: $229 \mathrm{~g}$ \\
R2: $\mathbf{5 7} \mathrm{g}$ & R3: $147 \mathrm{~g}$ & R3: $\mathbf{3 9 5} \mathrm{g}$ \\
Massa: $\mathbf{7 9} \mathbf{g}$ (b) & Massa: $\mathbf{1 6 4} \mathbf{g}$ (b) & Massa: $\mathbf{3 1 6} \mathbf{~ g}$ (a) \\
\hline
\end{tabular}

Médias seguidas de mesma letra não diferem estatisticamente ANOVA $(p=0,003)$

*Médias seguidas de mesma letra não diferem estatisticamente entre si, pelo teste Tukey a nível de significância de $5 \%$.

não tenham sido dosadas as concentrações de metais pesados gerados pelo intenso tráfego veicular nas folhas de C. scorpioides, pode-se inferir que os menores valores obtidos para o rendimento da massa seca e do óleo essencial, podem ser explicados possivelmente pela dispersão dos poluentes oriundos do tráfego veicular. Wójcik et al. (2005) citam que metais pesados nas plantas, promovem alterações na redução do crescimento, fisiologia, produtividade e alterações morfológicas. Constatou-se pelo teste ANOVA as diferenças no rendimento do óleo essencial nas estações estudadas, (Tabela 1 e Tabela 2), demonstrando que C. scorpioides cultivada em ambiente com baixo tráfego de veículos Urbanova (E3), diferiu estatisticamente das demais estações, apresentando rendimento máximo, $0,284 \mathrm{~g}$. $\mathrm{Na}$ estação Dutra (E1), maior trafego veicular, verificouse a menor produção do óleo essencial $(0,014 \mathrm{~g})$, seguida da Teotônio (E2), com 0,030 g, sugerindo que os poluentes como o ozônio troposférico (O3) sendo uma molécula reativa com compostos orgânicos, pode interferir na rota do metabolismo secundário e na produção dos compostos como terpenos, alcalóides e fenóis, presentes no óleo essencial de $C$. scorpioides.

Resultados semelhantes são observados na Tabela 3, onde o rendimento bruto do extrato obtido a partir de $10 \mathrm{~g}$ de folhas secas foi maior, $18,45 \%$, na estação Urbanova (E3) com baixo tráfego de veículos, quando comparada com a Dutra (E1) 1,3\% e Teotônio (E2) 15,98\%.

Santana (2013) não observou diferenças estatísticas no rendimento do óleo essencial de três populações de Bacharis reticularia (Asteraceae), cultivadas em três fazendas isoladas do contato com intenso tráfego de veículos no Distrito Federal. No presente estudo verificou-se que $C$. scorpioides (Asteraceae) cultivadas na estação Urbanova (E3), foi a que apresentou o maior rendimento de material fresco, material seco, óleo essencial e extrato (Tabelas 1, 2 e 3), sugerindo que a poluição oriunda do intenso tráfego veicular, pode interferir na fisiologia e na rota bioquímica das plantas da família Asteraceae.

Gobbo-Neto \& Lopes (2007) mencionam que a síntese de metabólitos secundários é afetada pelo ambiente onde a planta é cultivada, pela poluição oriunda do intenso tráfego de veículos, principalmente pelos níveis elevados de ozônio troposférico $\left(\mathrm{O}_{3}\right)$ e de monóxido de carbono (CO) no metabolismo de derivados fenólicos, o que foi constatado no presente estudo conforme as diferenças encontradas tanto no rendimento das folhas frescas, folhas secas, obtenção do extrato e produção do óleo essencial de $C$. scorpioides.

Os menores rendimentos do óleo essencial observados nas estações Dutra (E1) $0,014 \mathrm{~g} \mathrm{e}$ Teotônio (E2) 0,030 g, podem estar relacionados com a poluição veicular. Baumback (1996) relata que os poluentes oriundos do tráfego veicular atuam nos espaços intracelulares podendo lesar estruturas celulares, interferir na anatomia e na fisiologia da planta promovendo alterações no processo de

TABELA 2. Rendimento ( $\mathrm{g}$ ) do óleo essencial de Cyrtocymura scorpioides cultivado nas diferentes estações Dutra (E1), Teotônio (E2) e Urbanova (E3). Obtido à partir de $100 \mathrm{~g}$ de folhas frescas.

\begin{tabular}{|c|c|c|}
\hline Dutra (E1) & Teotônio (E2) & Urbanova (E3) \\
\hline R1: $0,014 \mathrm{~g}$ & R1: $0,036 \mathrm{~g}$ & R1: $0,251 \mathrm{~g}$ \\
\hline R2: $0,015 \mathrm{~g}$ & R2: $0,025 \mathrm{~g}$ & R2: $0,298 \mathrm{~g}$ \\
\hline R3: $0,015 \mathrm{~g}$ & R3: $0,031 \mathrm{~g}$ & R3: $0,304 \mathrm{~g}$ \\
\hline Rendimento: $0,014 \mathrm{~g}$ (b) & Rendimento: $0,030 \mathrm{~g}^{(b)}$ & Rendimento: $0,284 \mathrm{~g}$ (a) \\
\hline
\end{tabular}

* Médias seguidas de mesma letra não diferem estatisticamente ANOVA $(p<0,001)$.

TABELA 3. Massa obtida do extrato concentrado de Cyrtocymura scorpioides cultivado nas diferentes estações Dutra (E1), Teotônio (E2) e Urbanova (E3).

\begin{tabular}{lll}
\hline Dutra (E1) & Teotônio (E2) & Urbanova (E3) \\
\hline $1,030 \mathrm{~g}^{(\mathrm{b})}$ & $1,598 \mathrm{~g}^{(\mathrm{b})}$ & $1,845 \mathrm{~g}^{(\mathrm{a})}$ \\
$10,3 \% \mathrm{(b)}^{(\mathrm{b})}$ & $15,98 \%^{(\mathrm{b})}$ & $18,45 \%{ }^{\text {(a) }}$ \\
\hline
\end{tabular}

*Médias seguidas de mesma letra não diferem estatisticamente $(p<0,001)$ 
fotossíntese e afetando a rota do ácido mevalônico no qual são sintetizados os terpenos, dessa forma justificando o baixo rendimento do óleo obtido no presente estudo.

As reações entre os compostos orgânicos e o ozônio troposférico $\left(\mathrm{O}_{3}\right)$ oriundos do tráfego veicular, incluem a inserção de oxigênio em anéis benzênicos, a quebra de duplas ligações e a oxidação de álcoois, assim, quebrando as duplas ligações de compostos orgânicos pertencentes na rota metabólica do mevalonato precursores dos terpenos e provocando baixo rendimento do óleo essencial das plantas (Gillespie, 2012).

Larcher (2000), Manning \& Feder (1980) descrevem que o ozônio troposférico $\left(\mathrm{O}_{3}\right)$ quando absorvido pelas plantas através dos estômatos, é rapidamente decomposto, formando o oxigênio molecular e peróxidos, que afetam à membrana plasmática e todas as biomembranas, portanto as alterações de $\mathrm{pH}$ e as alterações fisiológicas

A

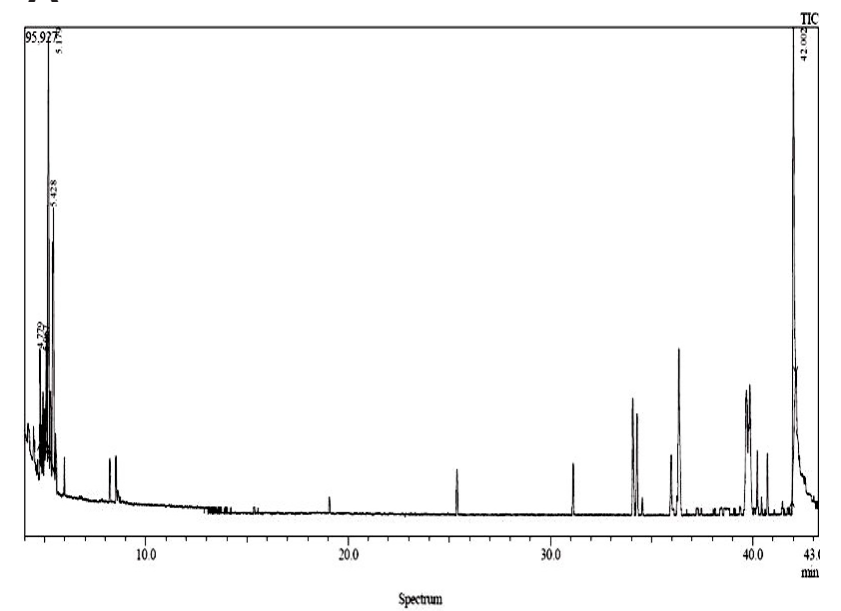

Spectrum causadas na planta pelo ozônio troposférico $\left(\mathrm{O}_{3}\right)$ pode justificar a alteração bioquímica na rota metabólica secundária de C. scorpioides, o baixo rendimento do óleo essencial e do extrato de $C$. scorpioides quando cultivada nas estações Dutra (E1) e Teotônio (E2), (Tabelas 2 e 3).

Observa-se nos cromatogramas das estações E1 e E2 (Figura 1A e 1B) a ausência dos principais constituintes encontrados no óleo obtido da estação Urbanova (E3), (Figura 1C). Os componentes encontrados nas estações (E1) e (E2), não puderam ser identificados, porém a análise realizada por similaridade dos espectros de massa atômica, identificou compostos como óxido de etileno e certos ácidos carboxílicos. O óleo extraído das plantas cultivadas na estação (E3), (Figura 1C), demonstra a presença de componentes característicos do óleo essencial de C. scorpioides, tais quais: $(\mathrm{A}: \beta$-cariofileno, $\mathrm{B}$ : $\alpha$-cariofileno, $\mathrm{C}$ : $\gamma$-elemeno ou Germacreno-B, D: $\Delta$-cadineno, E:

\section{B}
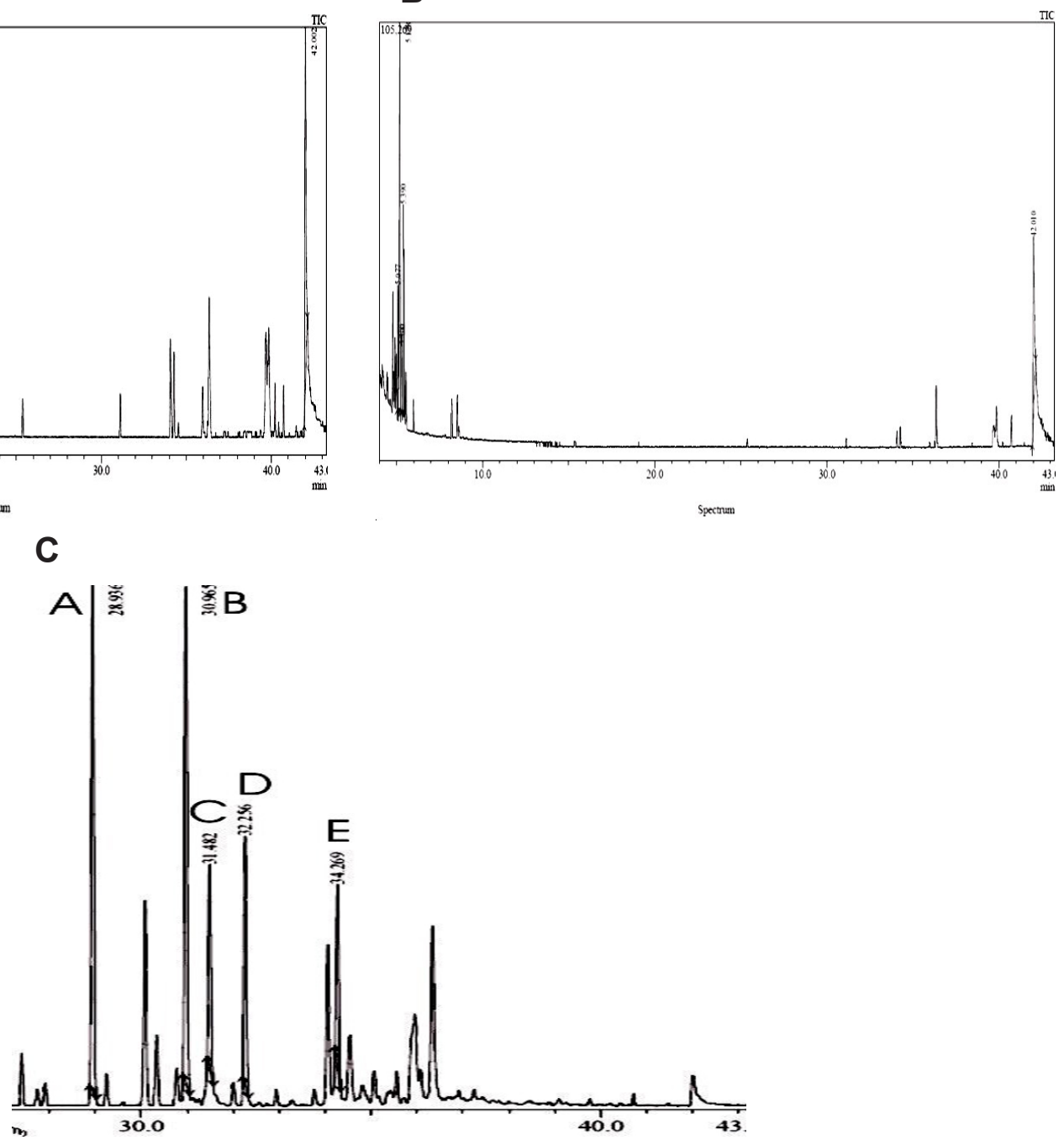

FIGURA 1. Cromatograma CG-MS do óleo essencial de C. scorpioides extraído das estações: A) Dutra (E1), B) Teotônio (E2) e C) Urbanova (E3). 
TABELA 4. Possíveis constituintes do óleo extraído de C. scorpioides cultivada na estação Urbanova E3.

\begin{tabular}{lccc}
\hline Tempo de Retenção & Composto & Índice de Similaridade & Biblioteca \\
\hline 28,9 & $\beta$-cariofileno & $94 \%$ & Nist08.lib \\
30,1 & $\alpha$-cariofileno & $92 \%$ & Nist08s.lib \\
30,3 & Aromadendreno & $88 \%$ & Nist08.lib \\
31,0 & Germacreno-D & $93 \%$ & Nist08.lib \\
31,5 & $\gamma$-elemeno & $88 \%$ & Nist08s.lib \\
31,5 & Germacreno-B & $88 \%$ & Nist08.lib \\
32,3 & $\Delta$-cadineno & $89 \%$ & Nist08s.lib \\
34,1 & Spatulenol & $91 \%$ & Nist08s.lib \\
34,3 & Óxido de cariofileno & $84 \%$ & Nist08s.lib \\
36,1 & $\Delta$-cadinol & $80 \%$ & Nist08s.lib \\
36,3 & $\alpha$-cadinol & $85 \%$ & Nist08.lib \\
\hline
\end{tabular}

Óxido de cariofileno).

Devido as estações (Dutra) E1 e Teotônio (E2) serem localizadas em local com médio a intenso tráfego veicular, sugere-se que as diferenças obtidas no rendimento do óleo e do extrato da planta possam estar associadas à presença de elevadas concentrações de $\left(\mathrm{SO}_{2}, \mathrm{NOx} \mathrm{e} \mathrm{O}_{3}\right)$, podendo ter causado a interferência bioquímica no metabolismo secundário da planta, alterando a produção do óleo essencial. Como o ozônio $\left(\mathrm{O}_{3}\right)$ é um poderoso agente oxidante que reage rapidamente com compostos orgânicos causando danos no metabolismo das plantas (Pinto et al., 2010), é possível que este tenha interferido na síntese de moléculas como acetil-coenzima $\mathrm{A}$ e ácido pirúvico, afetando a rota sintética do mevalonato, que consequentemente reduz a biossíntese de terpenos no óleo essencial de C. scorpioides, justificando o seu baixo rendimento.

A enzima ATP citrato liase citosólica catalisa a formação de acetil-CoA, precursora intermediária para diversos compostos secundários e fitoquímicos, portanto, a interferência do ozônio $\left(\mathrm{O}_{3}\right)$ na Acetil-CoA, afetou todo o processo do metabolismo secundário, na rota do mevalonato e da produção dos componentes do óleo essencial de plantas expostas a elevadas concentrações de Ozônio troposférico $\left(\mathrm{O}_{3}\right)$, dióxido de enxofre $\left(\mathrm{SO}_{2}\right.$ ) e nitratos (NOx) (Gillespie et al. 2012; Simões \& Spitzer , 2004). Sendo a principal razão do baixo rendimento do óleo essencial da planta Cyrtocymura escorpioides cultivadas nas estações Dutra (E1) e Teotônio (E2), expostas à poluição veicular e ao ozônio troposférico $\left(\mathrm{O}_{3}\right)$. Os compostos não foram isolados para a realização de análises de ressonância, a identificação foi feita exclusivamente com base em CG-MS e comparação com informações pré-existentes sobre os principais constituintes químicos do óleo essencial do Piracá (Toigo et al. 2004).

No teste de difusão em disco, verificou-se que o diluente do óleo essencial de $C$. scorpioides, Dimetilsulfóxido (DMSO), no ensaio com C. albicans, não formou halos na placa controle. Observou-se que houve alteração pouco significativa no diâmetro do halo formado na placa com $140 \mu \mathrm{l}$ dos óleos testados das plantas cultivadas nas três estações. A Dutra (E1) apresentou halo de $6,3 \mathrm{~mm}$, seguida da Teotônio (E2) com 8,6 mm e Urbanova (E3) com 9,6 mm (Tabela 5), quando comparado com o diâmetro do halo formado de $18 \mathrm{~mm}$, na placa com $100 \mu \mathrm{g}$ de anfotericina B, utilizada para tratamento de Candidíase.

A diferença estatística observada entre as amostras não é significante como resultado, pois todas as amostras foram inferiores ao controle positivo (anfotericina B) mesmo estando $40 \%$ mais concentradas que o controle, de modo que pode se verificar que o óleo essencial de Cyrtocymura scorpioides apresentou baixa atividade antifúngica quando comparado com a anfotericina B.

Toigo et al. (2004) verificaram a existência das propriedades antifúngicas do extrato fluído

TABELA 5. Média do diâmetro dos halos formados pelos diferentes óleos cultivados nas estações E1, E2 e E3 de Cyrtocymura scorpioides sobre Candida albicans.

\begin{tabular}{lll}
\hline Dutra (E1) & Teotônio (E2) & Urbanova (E3) \\
\hline R1: $6 \mathrm{~mm}$ & R1: $8 \mathrm{~mm}$ & R1: $10 \mathrm{~mm}$ \\
R2: $7 \mathrm{~mm}$ & R2: $8 \mathrm{~mm}$ & R2: $9 \mathrm{~mm}$ \\
R3: $6 \mathrm{~mm}$ & R3: $9 \mathrm{~mm}$ & R3: $10 \mathrm{~mm}$ \\
Média: $\mathbf{6 , 3} \mathbf{m m}^{(\text {a) }}$ & Média: $\mathbf{8 , 6} \mathbf{m m}{ }^{(b)}$ & Média: $\mathbf{9 , 6} \mathbf{m m}^{(\mathrm{b})}$ \\
\hline
\end{tabular}

*Médias seguidas de mesma letra não diferem estatisticamente ANOVA $(p=0,001)$. 
de folhas e caules de C. scorpióides perante Penicilium citrinu, Aspergillus alutaceus e Candida albicans e demonstraram a atividade inibitória dos extratos clorofórmico e hexânico de C. scorpióides para Penicillium citrinum e Aspergillus alutaceus. Constatou-se que o óleo de C.scorpioides não apresentou ação fungicida expressiva quando comparado com a anfotericina B que apresentou halo de $18 \mathrm{~mm}$.

Tavares (2007) observou que o uso indiscriminado de medicamento no Brasil, para combater doenças causadas por fungos, deve-se a um diagnóstico suspeitoso, além do uso irracional de medicamentos, estes são alguns dos principais motivos que tornam as bactérias e fungos cada vez mais resistentes aos medicamentos existentes, dessa forma a descoberta de novos compostos bioativos de plantas medicinais, torna-se uma opção para o tratamento de infecções fúngicas. Os resultados estatísticos da citotoxicidade com o extrato tornou-se visível após a realização do teste de MTT que quantificou a atividade mitocondrial e determinou a viabilidade celular (Perez et al., 2008).

A

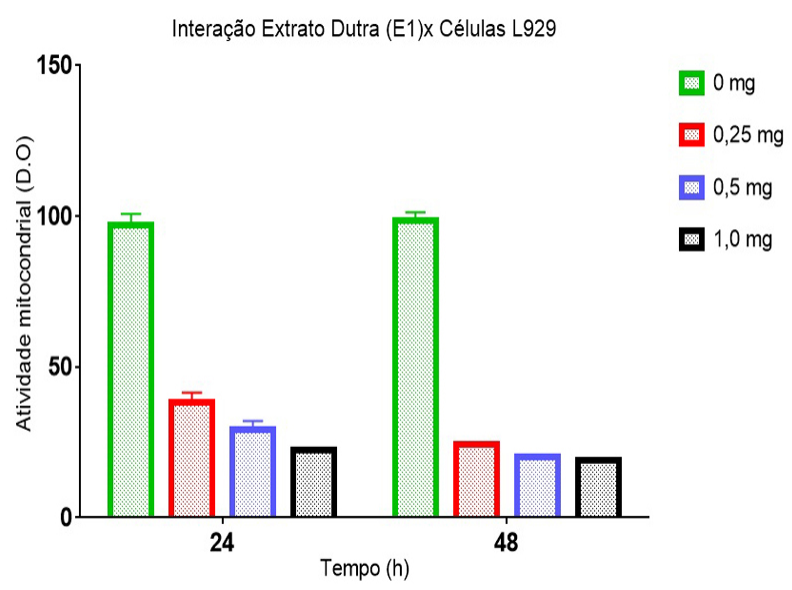

Observou-se maiores valores do índice citotóxico no período de incubação de $48 \mathrm{hs}$ nas duas linhagens, foi mais elevado na concentração de $1,0 \mathrm{mg} / \mathrm{mL}$ de extrato, com citotoxicidade nas linhagens de células de fibroblastos de camundongo L929 e de carcinoma de laringe humana HEp-2 respectivamente, (Figura 2).

Observou-se que as amostras de $C$. scorpioides cultivada nas estações (E1) e (E2), podem estar absorvendo poluentes emitidos pelos veículos, como o dióxido de enxofre $\left(\mathrm{SO}_{2}\right)$, monóxido de carbono (CO) óxido nítrico $\left(\mathrm{NO}_{2}\right)$ e o ozônio troposférico $\left(\mathrm{O}_{3}\right)$, sendo que a planta nessas condições de cultivo e exposição ambiental, pode produzir também compostos citotóxicos para células das linhagens L929 e HEp-2.

Silva (2012) indica as lactonas sesquiterpênicas (terpenóides), que são encontrados principalmente em plantas da família Asteraceae, como a Spilanthes oleracea (jambú), são capazes de inibir a ação da NS-KB, que induz a morte das células por apoptose. O que pode ter ocorrido, devido ao resultado obtido com o teste de citotoxicidade

\section{B}

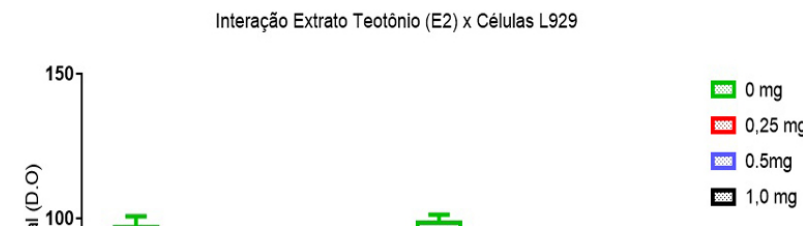

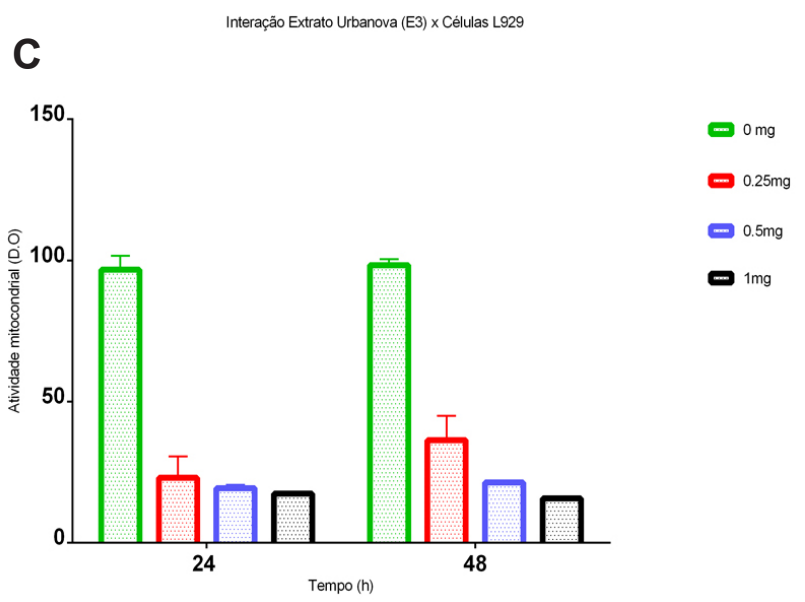

FIGURA 2. Teste de citotoxicidade interação extrato bruto solubilizado em álcool $70 \%$, nas concentrações 0,25 mg, 0,5 mg, 1,0 mg com células L929: A) Dutra (E1), B) Teotônio (E2) e C) Urbanova (E3). 
A

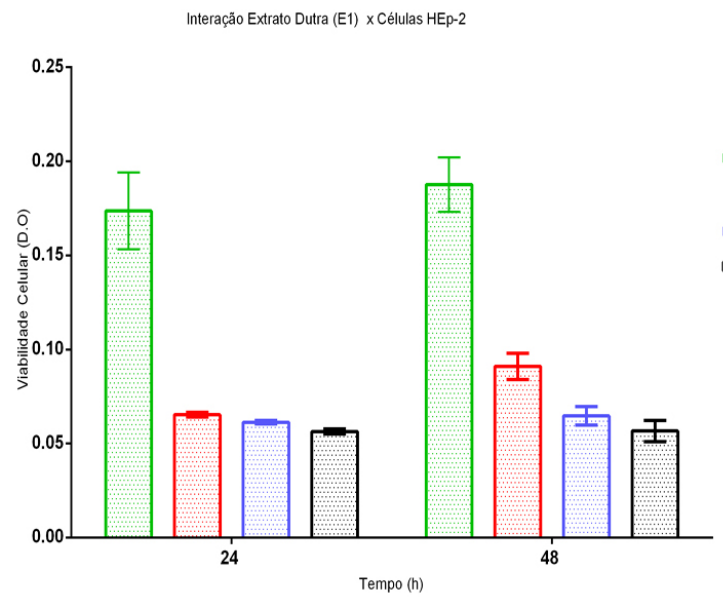

C

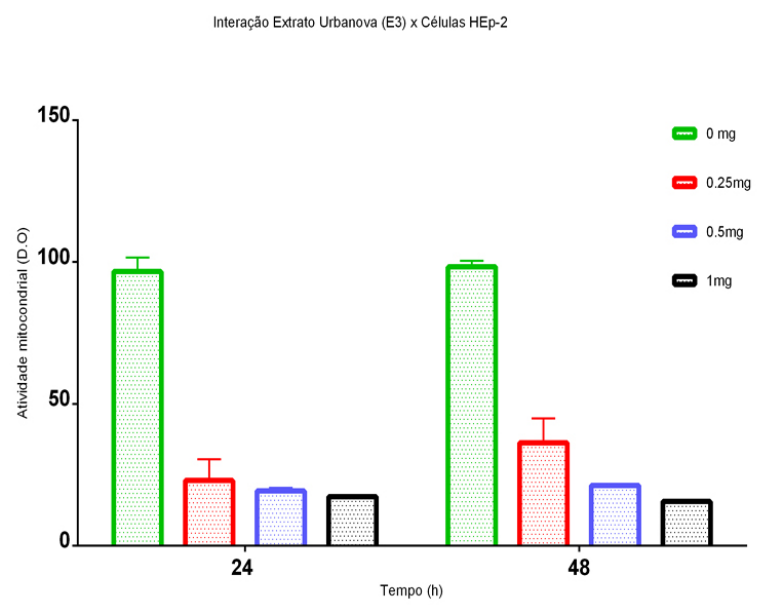

B
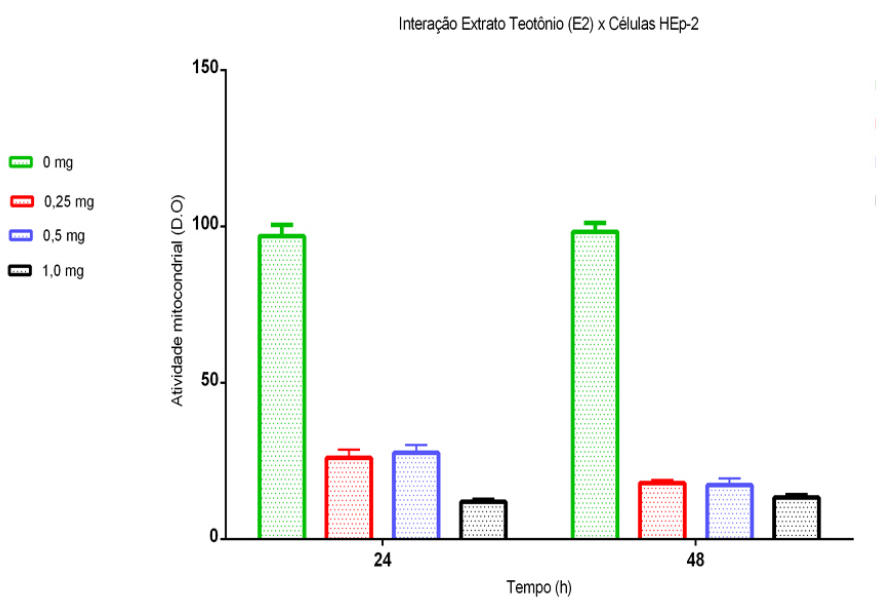

D

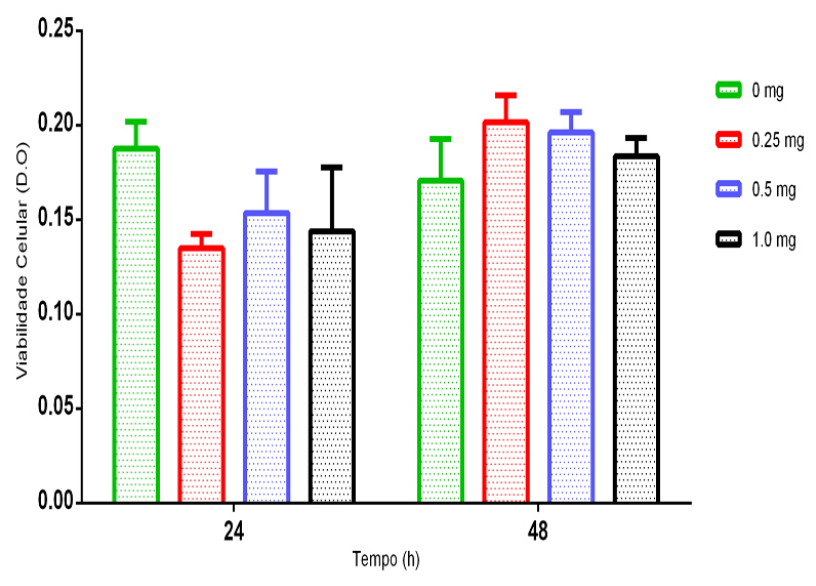

FIGURA 3. Teste de citotoxicidade interação extrato bruto nas concentrações $0,25 \mathrm{mg}, 0,5 \mathrm{mg}, 1,0 \mathrm{mg}$ com células HEp-2: A) Dutra (E1), B) Teotônio (E2) e C) Urbanova (E3), D) Controle: Citotoxicidade, interação álcool $x$ células HEp-2.

A

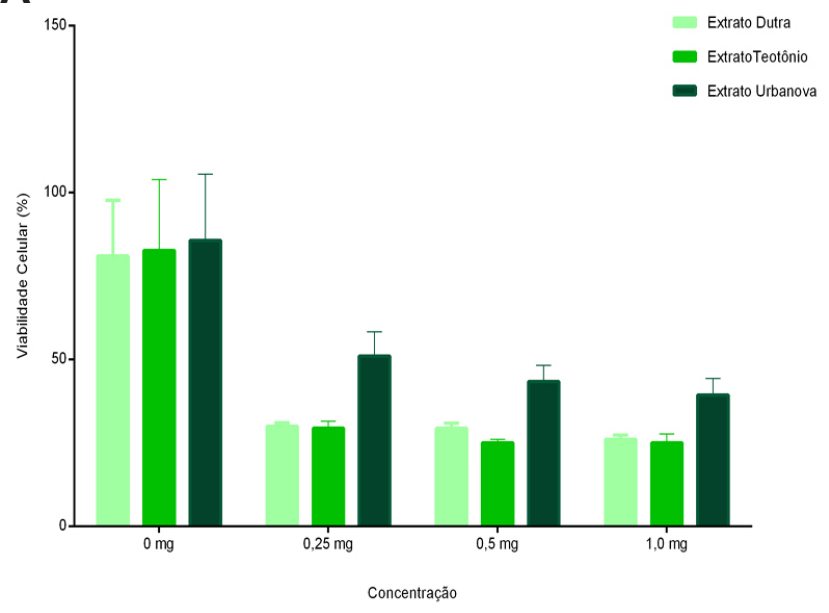

B

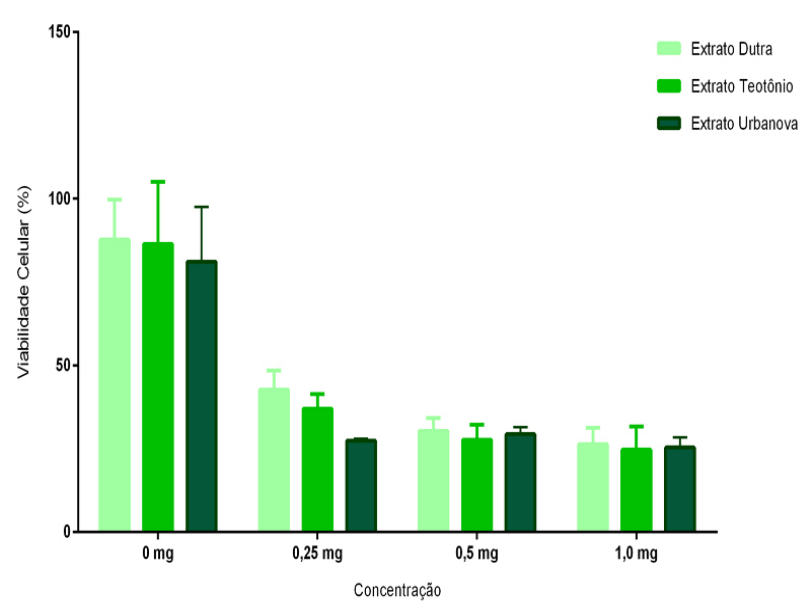

FIGURA 4. A) Comparação dos testes de citotoxicidade (células HEp-2) 24h e B) Comparação dos testes de citotoxicidade (células HEp-2) 48h. Nas concentrações do extrato: 0,25 mg, 0,5 mg, 1,0 mg. 
A

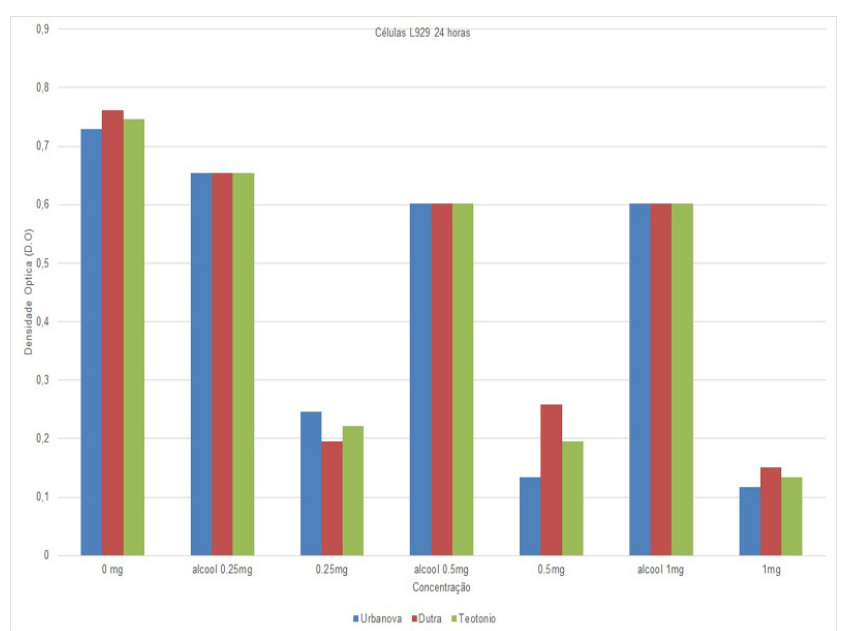

B

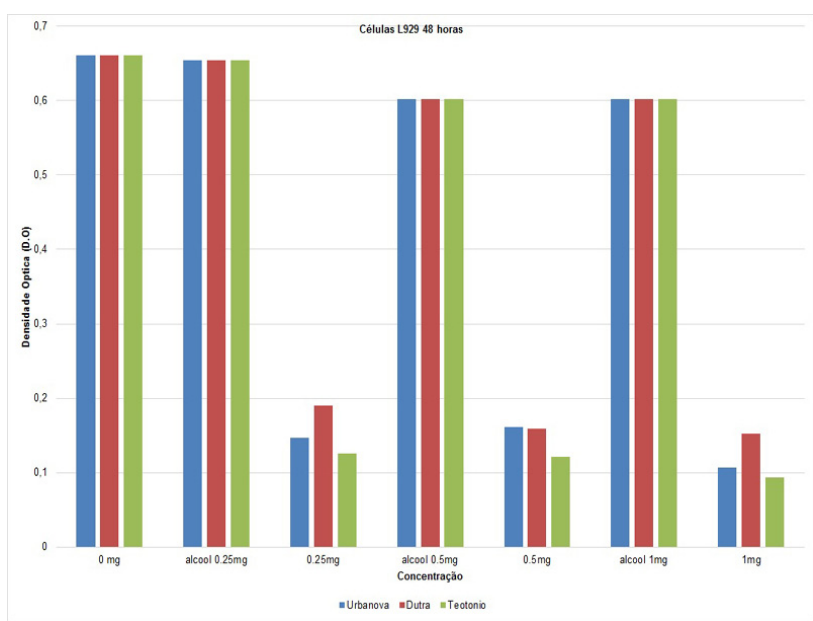

FIGURA 5. A) Comparação dos testes de citotoxicidade (células L929) 24h e B) Comparação dos testes de citotoxicidade (células L929) 48h. Nas concentrações do extrato: 0,25 mg, 0,5 mg, 1,0 mg.

realizado com o extrato de Cyrtocymura scorpioides (Asteraceae), testada nas linhagens celulares L929 e HEp-2.

Verificou-se que a concentração $0,25 \mathrm{mg}$ do extrato obtido das estações Dutra (E1) e Teotônio (E2), apresentou toxicidade significativa $(p<0,001)$ no período de 48 horas. O mesmo sendo observado na concentração de $1,0 \mathrm{mg}$ do extrato obtido na estação Urbanova (E3), quando comparado com o teste controle.

Os resultados demonstraram que, após a aplicação do extrato obtido das folhas de C.scorpioides, houve uma diminuição nas populações de células de fibroblastos de camundongo L929 e células de carcinoma de laringe humana HEp2 , em todas as concentrações testadas dos extratos obtidos das folhas da planta Cyrtocymura scorpioides cultivadas nas estações: Dutra (E1), Teotônio (E2), Urbanova (E3) nos períodos de incubação (24 e 48 horas).

Observou-se que $C$. scorpioides cultivada nas estações (E1) e (E2) com alto e médio tráfego veicular, podem absorver poluentes emitidos pelos veículos, como o dióxido de enxofre $\left(\mathrm{SO}_{2}\right)$, monóxido de carbono (CO) óxido nítrico $\left(\mathrm{NO}_{2}\right)$ e o ozônio troposférico (O3), sendo assim, a planta nessas condições de cultivo e exposição ambiental, consegue produzir compostos citotóxicos para células das linhagens L929 eHEp-2.

Moreira (2010) relata a respeito de possíveis alterações cromossômicas nas plantas devido à presença de agentes mutagênicos na sua composição genética ou podem ter sido decorrentes do seu metabolismo, esta mutação pode resultar da ação de compostos químicos externos como, poluentes ambientais, radioativos ou da estabilidade intrínseca dos ácidos nucleicos da planta, o que pode resultar na alteração do metabolismo secundário fazendo com que a planta produza e apresente compostos citotóxicos.

A atividade citotóxica dos flavonóides encontrados na família Asteraceae, testados em células tumorais tem sido descritas em diversos estudos, como exemplo temos os experimentos de Sonoda et al. (2004) onde foram testados 17 flavonóides em células de leucemia humana (HL60) e destes 17 flavonóides, 10 apresentaram considerável citotoxicidade.

Conforme observado, os flavonóides encontrados em C. scorpioides, podem ter influenciado na ação citotóxica nas células de fibroblastos de camundongo L929 e células do carcinoma de laringe humana HEp-2. A exposição à poluição veicular interfere preferencialmente na biossíntese de terpenos, notoriamente sobre a produção do óleo essencial, mas minimamente sobre outros metabólitos secundários, tais como os compostos citotóxicos listados anteriormente.

\section{CONCLUSÃO}

O ambiente com baixo tráfego veicular, estação Urbanova (E3), promoveu maior rendimento em massa de matéria seca, do extrato bruto e do óleo essencial da planta Cyrtocymura scorpioides.

A síntese do óleo essencial de $C$. scorpioides cultivada em ambiente com intenso tráfego de veículos, foi afetada. O óleo essencial possui baixa ação fungicida em comparação com a anfotericina $\mathrm{B}$ e o extrato hidroalcóolico é citotóxico para células de fibroblasto de camundongo L929 e de carcinoma de laringe humana HEp-2, independente do local 
de cultivo, com intenso ou baixo tráfego veicular. Entretanto a planta se tornou mais tóxica pelas condições do local de cultivo onde houve maior absorção dos poluentes gerados pelo intenso tráfego de veículos na estação Dutra (E1).

Para fins terapêuticos, C. scorpioides cultivada em ambientes com intenso tráfego de veículos, apresentou alterações na síntese metabólica do óleo essencial e dessa forma não deverá ser utilizada popularmente, pois as suas propriedades biológicas atribuídas ao óleo essencial diminuem.

\section{AGRADECIMENTO}

Coordenação de Aperfeiçoamento de Pessoal de Nível Superior (CAPES) pelo apoio financeiro. Universidade do Vale do Paraíba (UNIVAP) pela infra-estrutura.

\section{REFERÊNCIA}

ALVAREZ, A.S. et al . Avaliação das estruturas secretoras de Ocimum gratissimum var. macrophyllum Briq. (Lamiaceae) após extração dos constituintes voláteis. Revista Brasileira de Plantas Medicinais, v. 15, n. 2, p. 237-243, 2013.

BAUMBACK, G. Air quality control, formation and sources, dispersion, characteristics and impact of air pollutants: measuring methods, techniques for reduction of emission and regulation for air quality control. Berlin; New York: Springer, 1996. 490p.

BURGESS, D.S. et al., Pharmacodynamics of fluconazole, itraconazole, and amphotericin B against Candida albicans. Diagnostic Microbiology and Infectious Disease v. 36,p. 13-18, 2000.

BUSKUHL, H. Avaliação in vitro do mecanismo de ação citotóxica de lactonas sesquiterpênicas e outras substâncias isoladas de Vernonia scorpioides (LAM) PERS. 2007. 119p. Dissertação (Mestrado Ciências Farmacêuticas) - Universidade do Vale do Itajaí, Itajaí.

CARRENHO, L. Z. B. Avaliação dos efeitos da subfração acetato de etila III de Vernonia scorpioides em modelo de melanoma murinho in vivo e in vitro. 2009. 92p. Dissertação (Mestrado - Patologia Experimental e Comparada) - Faculdade de Medicina Veterinária e Zootecnia - Universidade de São Paulo, São Paulo.

CINTRA, A. B. P; DAMASCENO, F. L. Avaliação da atividade antimicrobiana de extratos hidroalcoólicos de Heliconia rostrata. In: SEMINÁRIO DE INICIAÇÃO CIENTÍFICA DA UNIFAL-MG, IV Jornada Científica e XIII Mostra de Extensão da Unifal-MG 2010.

DREUX, E.C. Avaliação do efeito antiinflamatório do extrato hidroalcoólico de Vernonia scorpioides (Lam.) Persoons em inflamação aguda. 2005. 85p. Dissertação (Mestrado - Ciências Biológicas) - Instituto de Pesquisa e Desenvolvimento, Universidade do Vale do Paraíba, São José dos Campos.

GILLESPIE, K. M. et al. Greater antioxidant and respiratory metabolism in field-grown soybean exposed to elevated $\mathrm{O} 3$ under both ambient and elevated $\mathrm{CO} 2$ concentrations. Plant, Cell \& Environment, v.35, n.1, p.169-184, 2012.

GOBBO-NETO, L.; LOPES, N.P. Plantas medicinais: Fatores de influência no conteúdo de metabólitos secundários. Química Nova, v.30, n.2, p.374-381, 2007.

LARCHER, W. Ecofisiologia vegetal. São Carlos: RIMA Artes e Textos, 2000. 531p.

MAIA, A.I.V. et al . Óleos essenciais das folhas de Vernonia Remotiflora e Vernonia Brasiliana: composição química e atividade biológica. Química Nova, v. 33, n. 3, p. 584-586, 2010.

MANNING, W.J.; FEDER, W.A. Biomonitoring air pollutants with plants. London: Applied Science Publishers, 1980. 141p.

MORAES, M. R. O efeito da poluição aérea em alternanthera brasiliana. 2012. 81p. Dissertação (Graduação - Biologia) - Universidade do Vale do Paraíba, São José dos Campos.

MOREIRA, T. C. L. Interação da vegetação arbórea e a poluição atmosférica na cidade de São Paulo. 2010. 80p. Dissertação (Mestrado - Recursos Florestais) - Escola Superior de Agricultura "Luiz de Queiroz", Universidade de São Paulo, Piracicaba.

OLIVARES, E. The effect of lead on the phytochemistry of Tithonia diversifolia exposed to roadside automotive pollution or grown in pots of Pb-supplemented soil. Brazilian Journal of Plant Physiology, vol.15, n.3, p.149-158, 2003.

PEREZ, L. A. B. et al. Padronização do teste do MTT em modelo de preservação a frio como instrumento de avaliação da viabilidade celular renal. Jornal Brasileiro de Nefrologia, v.30, n.1, p.48-53, 2008.

PINTO, D. M.; et al., Plant Volatile Organic Compounds (VOCs) in Ozone (O-3) Polluted Atmospheres: The Ecological Effects. Journal of Chemical Ecology, v. 36, n. 1, p. 22-34, 2010.

SANTANA, H. C. D. Caracterização química do óleo essencial de Baccharis reticularia DC. (Asteraceae) em função de diferentes procedências e da sazonalidade no Distrito Federal. 2013. 73p. Dissertação (Mestrado - Agronomia) - Universidade de Brasília, Brasília.

SÃO PAULO. Companhia Ambiental do Estado de São Paulo - CETESB. Relatório de qualidade do ar no estado de São Paulo - 2012. Disponível em: <http://www.cetesb.sp.gov.br/ar/qualidade-do-ar/31publicacoes-e-relatorios>. Acesso em: 20 out. 2013

SILVA, C. G. P.; Avaliação da citotoxicidade do extrato de spilanthes oleracea e seu potencial uso no tratamento do câncer. 2012. 70p. Dissertação (Graduação - Biologia) - Universidade do Vale do Paraíba, São José dos Campos.

SIMÕES, C.M.O.; SPITZER V. Óleos voláteis. In: SIMÕES, C.M.O; et al. Farmacognosia: da planta

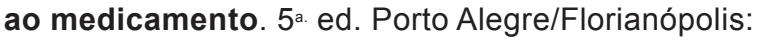
UFRGS/UFSC. 2004. p 387-415.

SONODA, M. et al. Cytotoxic Activities from two Scuttellaria plants in chinese medicine. Journal of 
Ethnopharmacology, v.91, n.1, p.65-68, 2004.

TAVARES, W. Antibióticos e quimioterápicos para uso clínico. São Paulo: Atheneu, 2007. 344p.

TOIGO, L. et al. Caracterização farmacobotânica, estudo do óleo essencial atividade antimicrobiana da erva-deSão-Simão Vernonia scorpioides (Lam.) Pers. Revista Brasileira de Farmácia, v. 85, n.2, p.49-55, 2004.

VASCONCELOS J, A. A.; MENEZES, E. A.; CUNHA, F. A.; CUNHA, M. C. S. O. ; BRAZ, B. H. L.;CAPELO, L. G.; SILVA, C. L. F. Comparação entre microdiluição e disco difusão para o teste de susceptibilidade aos antifúngicos contra Candida spp. SEMANA: CIÊNCIAS BIOLÓGICAS E DA SAÚDE, Anais, Londrina, v.33, n. 1, p. 135-142, 2012.

VASINCU, A. et al., Vernonia kotschyana Roots: Therapeutic Potential via Antioxidant Activity Molecules, v.19, p.19114-19136, 2014.

WÓJCIK, M. et al. Cadmium tolerance in Thlaspi caerulescens. Environmental and Experimental Botany, v.53, n.1, p.163-171. 2005. 